\title{
Enhancing The Façade Performance Of Existing Buildings Through The Integration Between Smart Materials \& Parametric Geometries In Architecture
}

\author{
Assistant.Prof. MOHAMED REDA \\ ABDALLAH ALI \\ Department of Architecture \\ Faculty of Engineering \\ Cairo University, Egypt
}

\author{
Eng. AHMED KHALED YOUSSEF \\ Department of Architecture \\ Faculty of Engineering \\ Cairo University, Egypt
}

\begin{abstract}
The study introduces new techniques of applying sustainable smart materials on existing buildings which will give them the ability to adapt passively with the surrounding environment and climate, reach the comfort zone inside the buildings automatically without occupants' interference. This research will present guidelines on way of using smart materials, assembling them in various geometrical composites, and how to apply them on the exterior building envelope, to reach optimum level of comfort without human interference. This prolific scientific thinking offers a specific procedure to use smart materials in building external envelope in hot climate and this by its turn will enhance temperature, lighting, and other comfort factors inside the building to reach the comfort range, and it will also decrease building economics and energy consumption as well. The research closes with the synthesis of the preliminary guide lines that will help architects to enhance existing building to become smarter or/and make a new building from the very beginning with these intelligent materials. Conclusion were educed according to analytical study of international case studies. International case studies have a lot of smart aspect for building façade that was evaluated according research new model. Local proposal was implemented and analyzed in a way to apply this smart material on it and what is the main effect of applying these smart new materials on existing material.
\end{abstract}

KEYWORDS: Smart materials, building façade, adaptive façade, responsive façade, Self-cleaning material, Phase change material (PCM), advanced geometries, Materialism, Property changing material, energy exchanging material, Shape morphing materials.

\section{ملخص البحث}

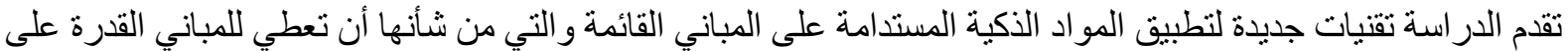

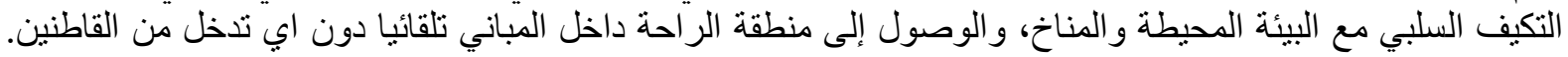

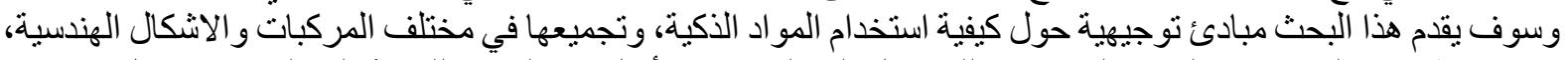

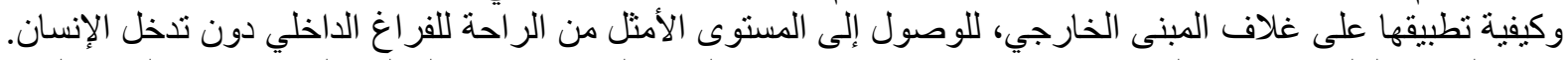

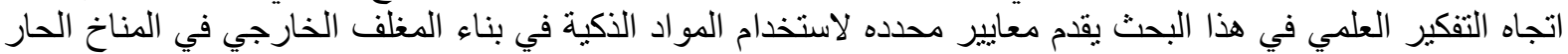

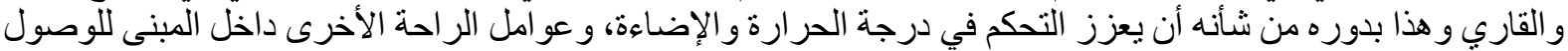

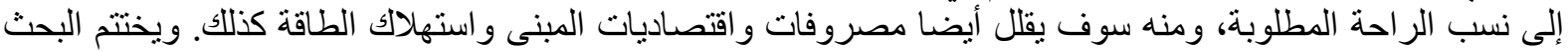

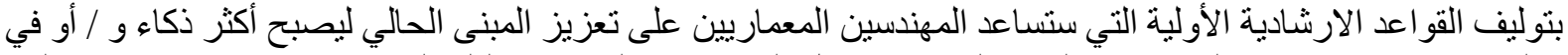

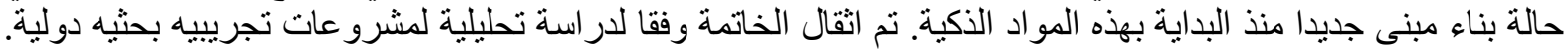

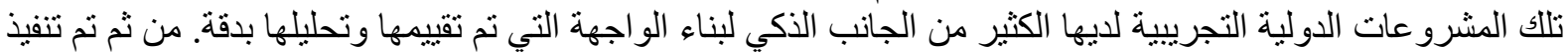

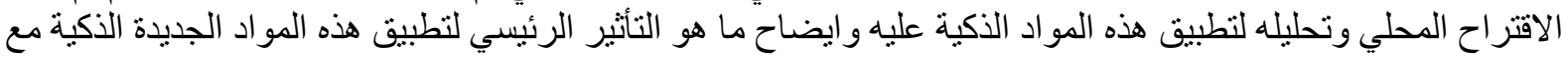

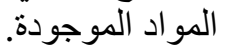

\section{INTRODUCTION}

During the 21st century sustainable design techniques were introduced to architecture, focusing mostly nowadays on how to develop a sustainable building that adapts on the surrounding environment without human interference to reach a comfort zone easily 
and quickly with minimum energy consumption. Reaching a comfort zone inside buildings consume huge amount of energy and need human manual techniques to reach suitable atmosphere, so new techniques and materials are needed to reduce the consumption and to facilitate reaching the comfort zone.

Hence there are two tracks to make a building responsive to the environment and achieving thermal comfort. The first track is using active techniques, in which there is an addition to the building to act smart. For example, photovoltaic panels may be added to help the building generate energy from a renewable resource. Active techniques include using mechanical shading systems as a mean to implement thermal comfort inside the building. The other track is to use passive techniques. This includes all design-based solutions to help the building to act smart by reducing the energy consumption. It includes for example reaching a building orientation, proportions, form and massing for thermal purposes. Also, it includes using responsive materials that act passively to the surrounding environment. These materials are fully independent system responding to the environment spontaneous and natural without using of electric energy, sensors or devices.

\subsection{The Main Objective of The Research}

The main objective is introducing and creating a matrix that represent the new techniques of applying and implementing smart materials within advanced geometries on existing buildings which will enhance and get the maximum of their abilities to adapt passively with the surrounding environment and climate, reach the comfort zone inside the buildings automatically without residents' interference. The objective will be gained through analyzing recent experimental case studies that focused on creating smart geometry by integrating smart materials into them. Ending with creating a prototype and guideline of creating an advanced geometry supported by a framework of applying these geometries and how to implement different smart materials' types into them to create a Smart Shape morphing material.

\section{FAÇADE: THE SECRET OF THE INNER COMFORT}

\subsection{The Façade as A Connector Between Inside and Outside}

The building façade as a rule can be comprehended as a skin, like the skin of any creature. It is the part of the building that encases the building, and should have the capacity to proficiently shield from every single outer impact, for example rain, sound, temperature and wind. In any case, transparent zones in the façade likewise act as the main contact between the outside and the inside of

the building. Besides, the façade must have the capacity to exchange air and sunshine into the space to guarantee a sufficient comfort level for

Fig. 1 Revival of the Casino of Montréal. Source: twinyc.com/113dzQ8_t8p78c3i1/ [Date Accessed: $15 / 11 / 20171$

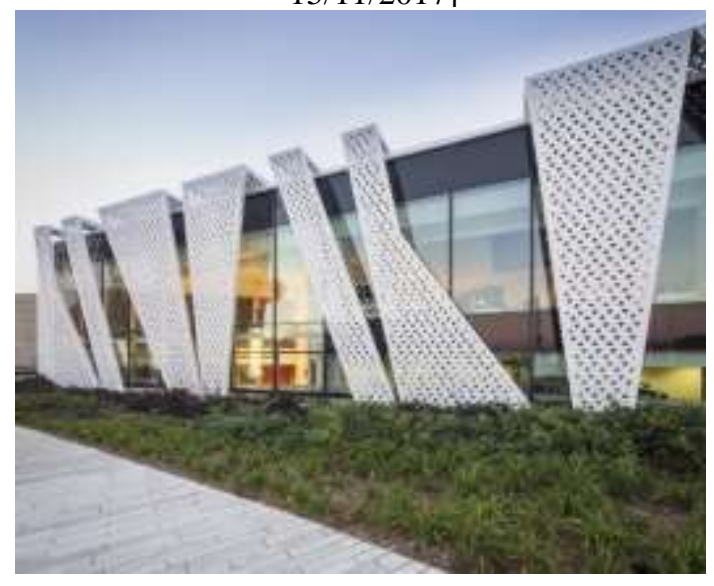

the occupant. Along these lines, the façade serves the capacity of an interface between the inside and the outside. Since the Nineties, structures with expansive glazed regions make the picture of urban areas in Central Europe. Many of these exceedingly glazed buildings have 
cutting edge façades that react to changing external conditions, for example, shifting temperatures, radiation, light and wind.

The main aspects that façade can affect to enhance the inner comfort are:

- Buffer and regulator * Thermal requirements

- Visual Needs

* Hygienic requirements

- Acoustic requirements

\subsection{The Façade as a Main Component of Adaptive Architecture}

"Adaptive architecture is defined as an architecture of which specific building components can adapt in response to changing stimuli, such as user input and environmental aspects. These adaptations can be found in different components of the building system. Additionally, adaptation can be envisioned on different technical levels. A door can be opened or closed. This performance can be executed by human power (manually control) or automatically by electric power (sensor detects approach and door opens). The levels of adaptive architecture are categorized to gain insight into the application of different techniques and performances in the building system. Adaptive architecture is utilized as a coordinating term for the different levels of architectural adaptation." ${ }^{i}$

In the accompanying, Aadaptive-Architecture is characterized and arranged by their 'technical specifications'. Fig 2 appears, the variable levels of Adaptability. These levels depend on the performative and innovative parameters which demonstrate a particular character. The performative and more advancement headways increment as far as level of complication from left to right.

Fig. 2 Levels of adaptation based on complexity. Source: ( Lelieveld, 2013 )

\begin{tabular}{|l|l|l|l|}
\hline Flexible & Active $\rightarrow$ Dynamic & Required technology \\
\hline & Control & Performance & Interactive \\
\hline \hline Flexible & Manual-Mechanical & Single-functional & Mechanical system \\
\hline Active & Manual-Electric & Single-functional & Energy \& system \\
\hline Dynamic & Sensor & Single-functional & Sensor \& system \\
\hline Interactive & $\begin{array}{l}\text { System \& user } \\
\text { interface }\end{array}$ & $\begin{array}{l}\text { Single-functional, } \\
\text { multiple options }\end{array}$ & $\begin{array}{l}\text { Sensor \& system \& } \\
\text { interface }\end{array}$ \\
\hline Intelligent & $\begin{array}{l}\text { System \& user } \\
\text { interface }\end{array}$ & Multi-functional & Ubiquitous system \\
\hline Smart & Ubiquitous & Multi-functional & Artificial Intelligence \\
\hline
\end{tabular}

\section{- Flexible}

Flexible represent the basic alteration of simple particular building segments. This change is singularly controlled by the occupant. The building parts are alterable and enacted remotely by human power. Flexible building parts will just serve singular function. A case of a flexiblebuilding component is a space partition; it could be opened or shut by the inhabitant favourites. With a specific end goal to create flexible frameworks the specialized necessities are basically mechanical methods, for example, rails, slides and hinges. 


\section{- Active}

An Active building part is completely controlled by the occupant, whereby a pre-set response is given to a particular order. The occupant is the initiator of a pre-set execution. The order can be, for instance, given by clicking on a button or by using controller screen. This implies pushbutton innovation and Uls are imperative points of view for the acknowledgment of active adaptation. Framework innovation, for example, engine frameworks, create a vital part in the interpretation of the order into a specific activity. Also, existing a source of energy is mandatory to perform the order.

A simple case is the auto mechanized doors; it can be opened by the utilization of an electric component enacted by clicking on a button. It ought to be noticed that the occupant is completely responsible for the operations' execution, the system won't do anything without the active order from the occupant.

\section{- Dynamic}

At the point when a part of a building is dynamic, it can change its settings automatically without a control of the occupant. The building identifies a specific change and responds as needed based on orders indicated previously on a programmed customized system. The adaptive execution of the building is limited in a structure and modified previously. Progressions in PC and sensor innovation are required keeping in mind the end goal to build up powerful dynamic adaptation.

An electric automated sliding entryway can be viewed as a dynamic system. These entryways distinguish the approach of anybody by a sensor, after which the entryway opens without any interference from the user. After entering from the entryway, the door sides close in this manner. The entryway can be opened or closed as a response to a specific input; either it is a man moving toward the entryway or not. The framework will just respond to one information.

\section{- Interactive}

Interactive adaptation immediately responds on occupant activities or surrounding natural changes. It can react with the occupant or outer condition on an instance level. At the point when a specific circumstance reoccurs, the framework will recall the occupant's pre-sets and respond as needs be. The execution of the building is acknowledged on a single level. This shows just a single performative viewpoint is available. Improvements on interactive adaptations are identified with the mix of cutting edge PC frameworks in the building framework.i.

The entryway can clarify the standard of an interactive adaptation. An electric entrance can expand its' sides movement speed, by distinguishing the toward speed of the coming person. When moving toward quicker, the entryway opens quick. The person can thus modify the opening and shutting execution. Moreover, the interactive framework can detect that the entryway should open by a specific temperature, for ventilation needs. Additionally, the framework can decide if the individual moving toward the entryway needs to pass within the entrance, or just pass around the entryway's area without really entering. As far as operation, the entryway just opens and closes, however the way of opening and shutting depends on different factors. 


\section{- Intelligent}

"If the system adapts itself to the users' interests and interaction preferences and works cooperatively with the user to accomplish specific goals with the use of additional sources of knowledge to meet the needs of the user, a system is considered intelligent". iii Intelligent adaptation is best clarified by that meanings.

The building system has the ability to take the initiative to adapt and how to adapt. An intelligent system can detect that the door is open, even when nobody is passing and can thereupon close the door. If the user wants the door to be opened, for example for ventilation purposes, the system can adapt and learn that the door should stay open during the specific situation.

This outlines responses on re-happening circumstances won't really prompt a similar adjustment. The framework can gain new information from its surrounding or occupant wants and needs.

As all frameworks are coordinated and controlled by one intelligent framework, an enhanced execution of the building framework can be built up. This could be shown by a case of indoor comfort. By extensive the radiation, the sun shading will close consequently, the light framework turned on and the heating machines diminished. Furthermore, the thermalenergy can be saved and discharged amid circumstances when the decreasing of indoor temperature. Subsequently, all incorporated frameworks are collaborating and can be adapted for ideal execution. ${ }^{i v}$

\section{- Smart}

"Smart architecture has the ability to grow, evolve, adapt and learn. It shows self-initiative and has learning capabilities. In comparison to intelligent architecture, the system does not only learn by the actions of users or changes in the environment, but also evolves according to its own discretion. The smart system is completely integrated into the life and behaviour of the users and environment." $v$. The connection between the building framework and its client will wind up noticeably like human cooperation; the building will end up plainly receptive to feelings. To make smart-adaptive frameworks, new advancement techs are required which are not available nowadays. Information exchange is an imperative perspective for the improvement of smart adaptive systems. Improvements in Al and matter technologies are imperative prerequisites for the acknowledgment of Architecture which can perform smartly.

A Smart framework can be described by a Bio-mimicry framework, which can work with comparable standard as biological natural procedures. The inescapable frameworks can act like organisms which can develop, advance, and breathe like living life forms. The complication of organic procedures is regularly not completely well learned. Particularly on the level of executing this information into Smart Projects. Nonetheless, it proposes motivation for visionary engineers who envision developing structures and transformative architecture designs. A building that can construct itself and coming out from a core seed. The seed consists of an integrated code for the design, that saves all data of the building's functions and capabilities ${ }^{\mathrm{vi}}$. A building that can adjust spatially by reconfiguring its sub-atomic framework and can develop and self-heal just like any kind of living organisms. 


\section{SMART MATERIALS FUNDAMENTALS AS AN ADAPTIVE SYSTEM}

Based on a basic definition, smart materials are the matters which can react with the surroundings in a particular time and can make the opposite and adjust their inner properties

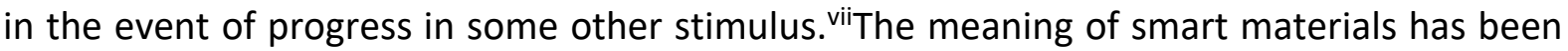
developed to a substance that diffuse, process, or receive a stimulus and react by creating a valuable impact. "Some of the stimuli that perform upon smart materials are strain, stress, temperature, chemicals (including $\mathrm{pH}$ stimuli), electric field, magnetic field, hydrostatic pressure, different types of radiation, and other forms of stimuli". viii NASA describes "smart materials as materials that "remember" configurations and can conform to them when given a specific stimulus." ix Encyclopedia of chemical technology defines that "smart materials and structures are those objects that sense environmental events, process that sensory information, and then act on the environment". ${ }^{\prime}$

\subsection{Smart Materials as an Architectural Definition}

In Architecture, Smart-materials are high-tech materials that when attach to a building they react smartly to the surrounding changes in atmosphere, in All seasons even the climate is hot or cool to make it comfort or to reach the needs of users inside it. The expression 'Smart materials' is relevant to materials and frameworks that can automatically respond to make changes to the interior envelope through specific material related properties and combinations.

Smart-Materials are regularly thought to be a coherent expansion of the direction in materials advancement toward more specific and particular execution. From that aim, they are like living creatures, can perform both detecting, activating capacities and are fit for adjusting to changes of the surroundings. As such, these materials could adjust themselves in light of an outer stimulus or react to the stimulus by creating signs. By adjusting smart materials, a complex section in a framework comprising of individual units, detecting and inciting segments would now be able to do the same in just using a one unit, accordingly minimizing the total size and the complication of the framework. In any case, smart materials will never supplant ordinary framework completely; they for the most part will be a piece of some intelligent frameworks. Presently Architects could start to choose or design the main features of a superior material to match particularly characterized requirements.

\subsection{Main Characteristics Distinguishing a Smart Material}

Smart materials bring aspects that separate them from other materials. Fig. 3 below indicates the essential qualities that were well-defined concerning illustration differentiating a smart material from normal materials that utilized within construction.

characteristics could potentially be used to Possibly upgrade a material property on progressed temporary input states, also it alternately will improve specific activities by maintaining steady state circumstances in the surroundings.

As stated by separate stimulus-response, smart materials have the capacity on reversibly adjust their inner properties. If that property is in a molecule, a material, a composite, or a whole framework. There are Five Main Characteristics recognizing smart materials from the ordinary materials utilized within architectural needs described as below: 
- Immediacy: they react progressively in real time.

Fig. 3 Fundamental characteristics of Smart Materials. Source: researcher based on (Addington, 2005)

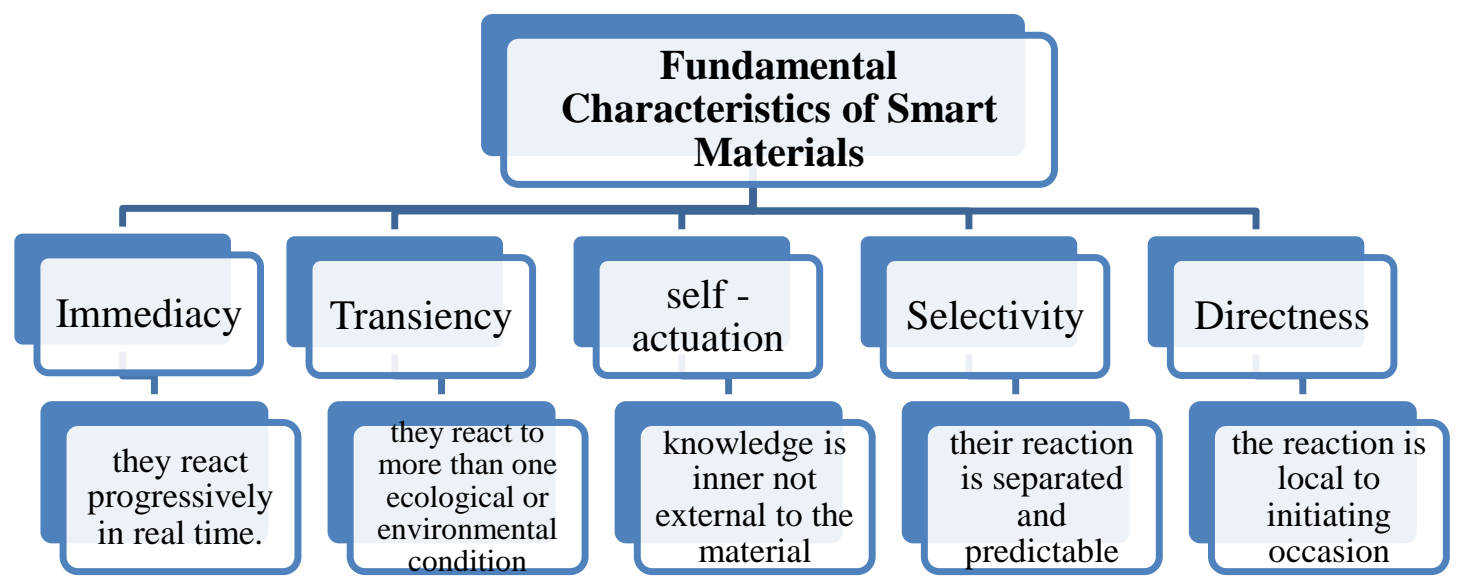

- Transiency: they react to more than one ecological or environmental condition.

- self-actuation: knowledge is inner not external to the material.

- Selectivity: their reaction is separated and predictable.

- Directness: the reaction is local to initiating occasion.

Smart materials could be gathered and ordered into Three Sections: 'Property change' ability, 'Energy exchange' ability, and 'Material Exchanges (Discrete size/location, - Reversibility)'. Those functions could possibly use to whichever enhance a material property on superior match temporary conditions or enhance specific practices to keep up consistent state conditions in nature.

Energy fields could be divided into a lot of forms of energy - potential, thermal, mechanical, electrical, chemical, and dynamic - at from claiming which might be alternately changed over as stated by "the First law of thermodynamics (the law of the conservation of energy)".

The physical attributes of smart materials are dictated by those energy fields and the system through which this energy contribution to a material is changed over. On the off chance that the system influences the materials' internal energy by adjusting either the material's atomic structure or microstructure then the outcome is a form of 'a property change' of the material. In the event that the system changes the energy condition of the material structure, yet does not modify the material itself, then the outcome is a form of 'an exchange of energy' from one form to another. "A simple way of differentiating between the two mechanisms is that for property change type, the material absorbs the input energy and undergoes a change, whereas for the energy exchange type, the material stays the same but the energy undergoes a change. We consider both of these mechanisms to operate at the micro-scale, as none will affect anything larger than the molecule, and furthermore, many of the energy-exchanges take place at the atomic level. As such, we cannot 'see' this physical behavior at the scale at which it occurs." ${ }^{\prime \prime}$ 


\subsection{Types of Smart Materials}

They are arranged in bunches into Two fundamental groups that mirror their conduct and method for working in view of the two essential classes of smart-materials talked about above - Those groups have been called Type 1 and Type 2 materials:

- Type 1: a material which adjusts one of its inner features such as chemical, mechanical, thermal or electrical, based on any change of the situations in its surroundings and that done without interference from extra controller. The inputted energy into the material make an effect on the material's internal energy by shifting the microstructure of the material and the outcome formed in a property change of the material it-self Fig. 4.

Fig. 4 The input/output control models for smart materials type-1.

Source: (Addington \& Schodek, 2005)

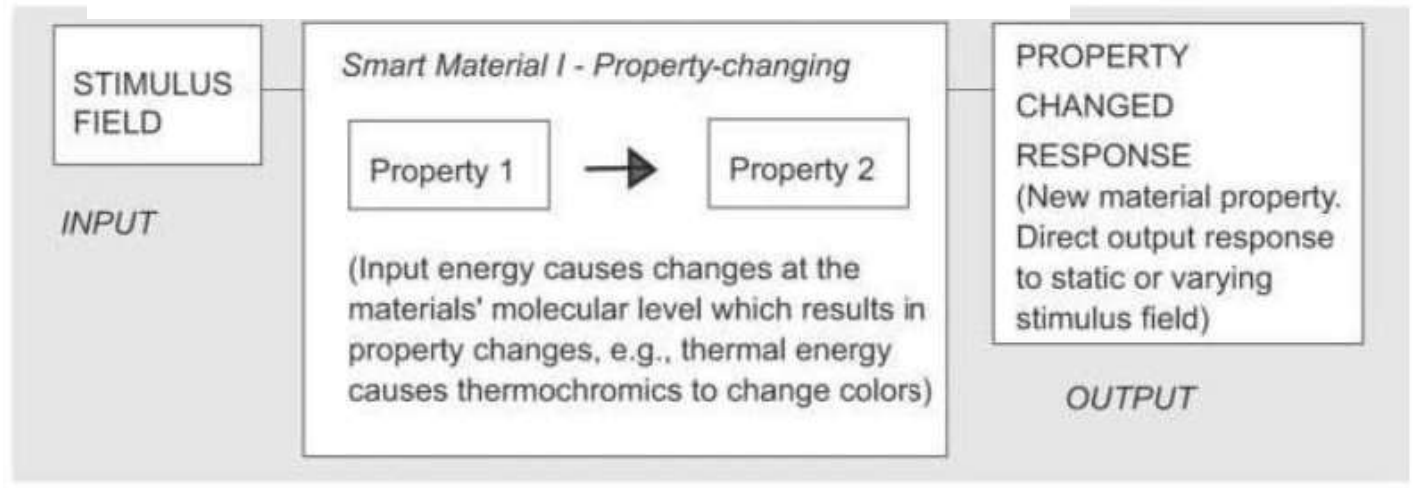

- Type 2: a material or gadget which alters energy from a phase to another one to have an effect on a required ending state. Energy inlet to the material make adjustments into the material composition's energy state, however it does not make changes in the material itself, the material remains as it is, but rather the energy experiences an alteration Fig 5.

Fig. 5 The input/output control models for smart materials type-2

Source: (Addington \& Schodek, 2005)

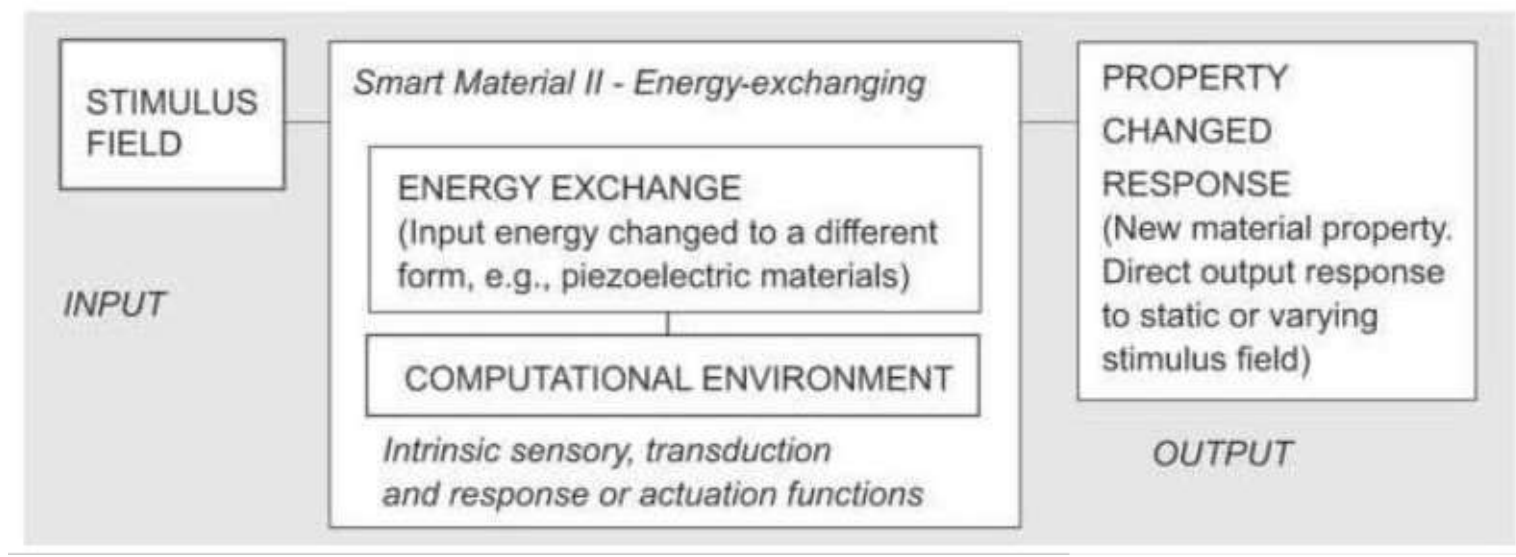


Concerning the Smart Material Types, the property change type has a lot of applications that could serve architecture and has the capability to react on different situations of surroundings changes and environmental adaptations. The energy exchange type can also react to an entering energy and based to the thermodynamic law, altering this energy into other phase of energy and that could be implemented through building services, for example in actuators and sensors. The type that reflects the reversibility feature and the capability to go back to its initial phase, Position and size are working as insulators. Fig 6 below shows the relation to input and output stimuli of all types of smart materials.

The most noticeable and can be clearly observed applications of smart materials are related to the façade system. Fig. 7 below shows the appropriate places to design and fix some types of smart materials on buildings façades.

Fig. 6 Types of smart materials: relation to input and output stimuli. Source: (Addington \&Schodek, 2005).

\section{TYPE OF SMART MATERIAL}

INPUT

OUTPUT

Type 1 Property-changing

Thermomochromics

Photochromics

Mechanochromics

Chemochromics

Electrochromics

Liquid crystals

Suspended particle

Electrorheological

Magnetorheological
Temperature difference

Radiation (Light)

Deformation

Chemical concentration

Electric potential difference

Electric potential difference

Electric potential difference

Electric potential difference

Electric potential difference
Color change

Color change

Color change

Color change

Color change

Color change

Color change

Stiffness/viscosity change

Stiffness/viscosity change

\section{Type 2 Energy-exchanging}

\section{Electroluminescents \\ Photoluminescents \\ Chemoluminescents \\ Thermoluminescents \\ Light-emitting diodes \\ Photovoltaics}

$\begin{array}{ll}\text { Electric potential difference } & \text { Light } \\ \text { Radiation } & \text { Light } \\ \text { Chemical concentration } & \text { Light } \\ \text { Temperature difference } & \text { Light } \\ \text { Electric potential difference } & \text { Light } \\ \text { Radiation (Light) } & \text { Electric potential difference }\end{array}$

Type 2 Energy-exchanging (reversible)

\section{Deformation}

Temperature difference

Temperature difference

Electric potential difference

Magnetic field

\footnotetext{
$\longleftrightarrow$ Electric potential difference

$\longleftrightarrow$ Electric potential difference

$\longleftrightarrow$ Electric potential difference

$\leftrightarrow$ Deformation

$\leftrightarrow$ Deformation
}

Electrorestrictive

Magnetorestrictive 
Fig. 7 the appropriate places to design and fix some types of smart materials on buildings façades. Source: researcher

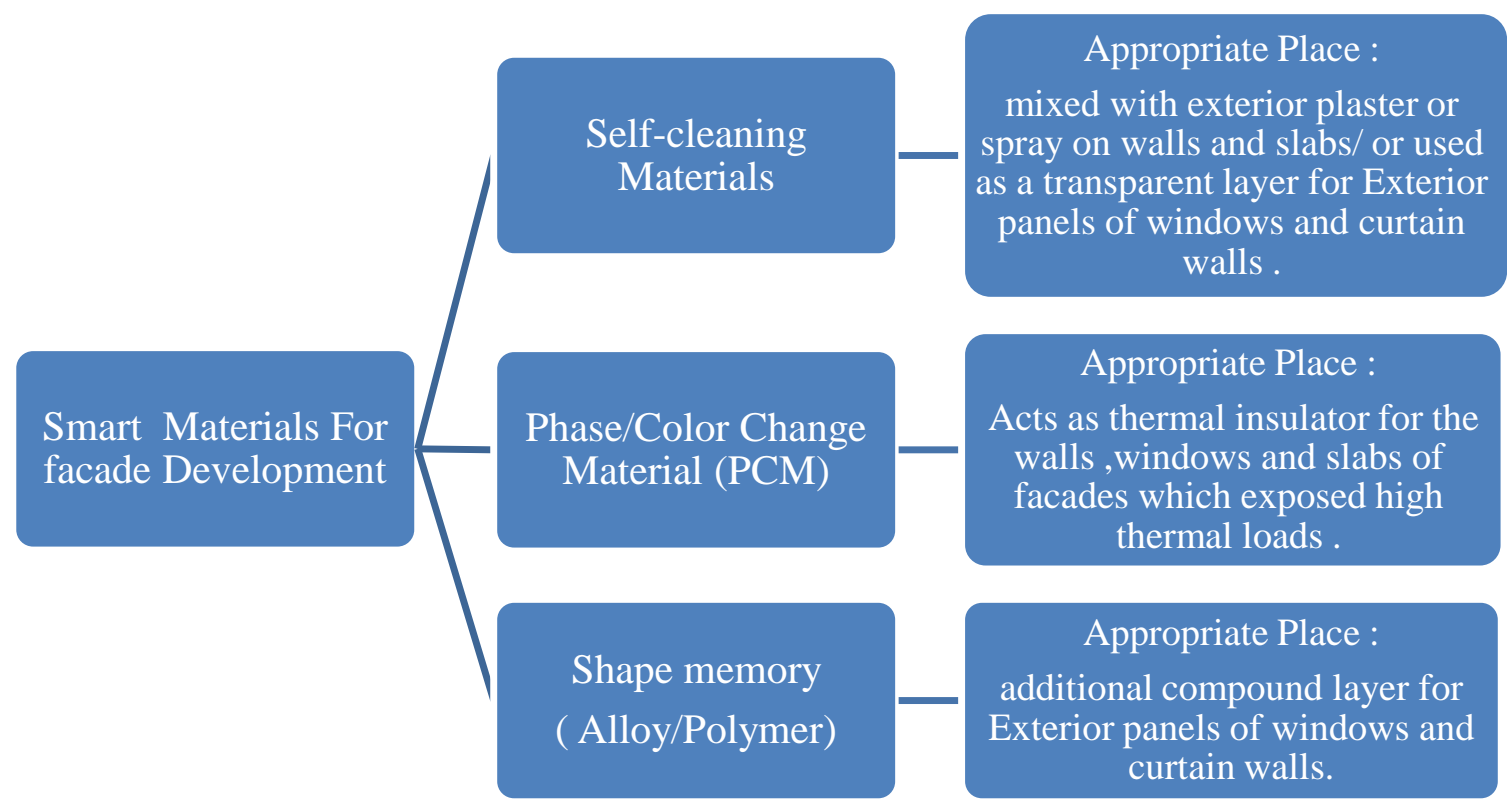

Smart materials and intelligent building systems lean towards to be extremely integrated within the building to preserve suitable interior conditions. Intelligent systems and Materials have to resist also wide range of temporary changeable exterior conditions. The integration of those dual general-requirements will lead to create buildings serve a sustainable human comfort. To achieve this objective for a particular function or application, the research will focus on Using Smart Materials as a key for Smart Geometries to create 'Shape Morphing Materials' with new features.

\section{SMART MATERIALS / GEOMETRIES EXPERIMENTAL CASE STUDIES}

\subsection{Double Face Project: Adjustable Translucent System To Improve Thermal Comfort}

The main goal of the double face project is improving and creating of a newly creation that specially for passive thermal comfort of interior and semi-interior area by ways of materials that has low weight and has the capability of storing of latent heat, though instantaneously permitting light of day to permit through as much as it can. Definitely that project purposes two main things: prototyping and designing an adaptable transparent integrated system containing thermal absorption and insulation in a standardized method, which is adaptable agreeing to various heat loads in summer and winter. The production comprised of demonstration of concept, a sequences of execution measurement and simulations, a prototype of an adaptable thermal mass system that based on lightweight and transparent materials

Fig. 8 DoubleFace: adjustable Trombe wall system. Source: ( Turrin \& Tenpierik , 2014 )

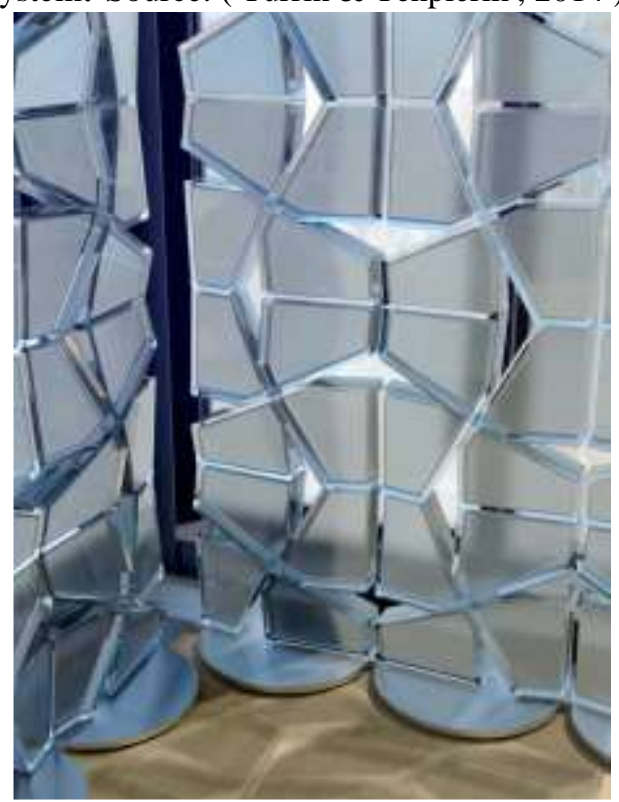


which is PCM material for storing latent heat and transparent aerogel units for thermal isolation.

- Concept:

Double Face is mainly depend on a creation method to thermal basics of Trombe walls. Comparing with the conventional Trombe walls so the system is:

- If comparing with the normal Trombe it will be found that It is light in weight by around five times to eliminate the overloads of buildings construction

- To get the maximum gain from daylight

- adaptation to standardize the thermal properties.

Applied material is considered is the main way in order to achieve the Transparency and Lightness. As another usage of materials that are weighty and impervious such as concrete, planning of a new a new innovate application aerogel and PCM. In the market there is a lot of products and technical system are existing as application of the phase changing material by applying it by mixing all of them into containers, walls, or system of airings or in facades. ${ }^{\text {ii }}$

There is the passive heat gain and passive cooling concepts, the passive heat gain is when the thermal mass exposed to the solar radiation of the winter while the passive cooling that is protecting the thermal mass from the summer and then performing as thermal buffer.

This happens by rotating the elements towards the source of incoming heat or the sink for heat release. In winter, the PCM side would face the exterior and be thermally charged during the day by the low winter sun. During night times, oriented towards the interior, it releases the accumulated heat. In summer, during the day in combination with external sun shading, it would store the heat from interior heat loads and during the night release this heat to the outside environment by means of night ventilation, thus acting as a cooling plate.

\section{- Method:}

The researchers of study began by a extensive inventory of current phase changing materials; an investigation of their characteristics; and then resulting a materials selected list. And for each one of the chosen phase changing materials, digital simulations were directed to evaluate the thermal performance. They were directed for only one layers of phase changing materials in many different widths and thickness, also for mixtures between 2 layers, one of phase changing materials in many different widths and thicknesses, one of transparent isolation and in many different widths and thickness. The transparent isolation was pretend as an Aerogel layer; and also as a hollows structure retention air with a transparent printed three-dimension material. In dependence with digital imitations, the layers classification was taken dimensions before for a thickness of $7 \mathrm{~cm}(5 \mathrm{~cm}$ PCM, $1 \mathrm{~cm}$ aerogel and $1 \mathrm{~cm}$ container wall thickness). Several samples $(17 \times 17 \times 7 \mathrm{~cm})$ were finished from a numerous of chosen phase changing materials. ${ }^{\text {iii }}$
Fig. 9 Double Face: unit details.

Source: ( Turrin \& Tenpierik, 2014 )

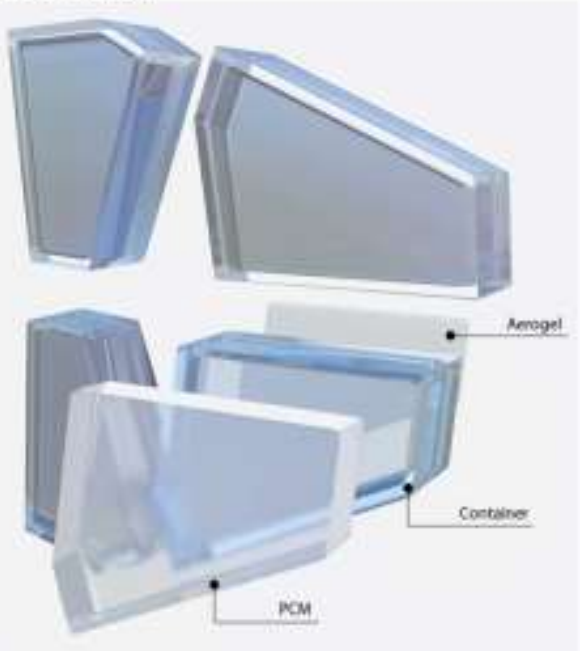




\subsection{Thermo-Bimetal Manipulation Project: Taming Thermo-Bimetal To Behave}

Thermo-Bimetal is known as type of smart material that twists and turns to cruel when it is exposed to heat, also it can give mechanically movement of its' surface for serving the building shadow, ventilation, self-assemble, reinforcement, and shape transformation. Also changing the character of molecular of the coated metal, its performance can be enhanced, improved, and also even annulled dependent on the shape as it shown in Fig 10.

From the start of Industrial Revolution, the Smart thermos bimetal began to be used, two metals sheets plating together with a variation in the thermal expansion coefficients for each one of them, so the material is exposed to heat or cold it deforms. And when the temperature increases, the expansion happens in a side of the laminated sheet greatly than the other side and that creates a curl within the sheet as an outcome from this composite.

The thermos-bimetal mixture that needed for the next studies, has the ranged as maximum deflection temperature of about $0^{\circ}-120^{\circ} \mathrm{F}$. Invar material is material that has lowexpansion that is an iron and nickel alloy, but nickel manganese alloy is the material that has a high expansion property. In order to overcome the corrosion, the nickel, chrome or copper are covered the material, the material can be customized at any thicknesses. Also, the deflection varies differs according to many elements such as size and shape, the temperature of air, and the clamping position and additionally the materials' thickness. ${ }^{\text {xiv }}$

About 3 investigations have been evaluated and analyzed; the factors are merged into a computerized definition of a one element just for tessellating a superior surface. Every separate element is made to act with very small difference from the other parts, that suggests an unlimited difference in the final form. ${ }^{\mathrm{xv}}$

The portion, the entire, the mechanism, the performance, the durability, and the same for all differences that embedded to the complication of this design technique. It is study a design model of those who have no scientific borders. ${ }^{\text {vi }}$ 


\section{- Using the Cantilever for Brise-Soleil Shading}

(“Bloom,” M\&A Gallery, Los Angeles, CA, 2011)

When contracting about one close end of about a ratio 1:6 strip material and permitting the other end to transfer easily, So the Thermo-bimetal curvature is in the best positioning and is the easiest way in that case the material twist in the longer dimension side with the less cross interference in this cantilevering configuration,

In fig. 70 it was shown that In the "Bloom" case, which is a pavilion made for shadow, illumination, and also for air ventilation, there are about 0.008 in. high thickness cross shaped parts fixed from three sides in position that permitting the remaining side to twist easily when it is exposed to the sun. The twisting part geometry purposefully prevents the sun. Analysis of the structure, perfect shapes and models of solar are joined among each other by computational instruments in order to define the resulting surface shape. Take in consideration the structure position, the treatable blinkers are lengthened because of increasing curvature, removed or hinged, removed for lightness and effectiveness of material, and hinged for structural supports.

\section{- Optimizing Flexivity for Opaque Transformations}

Fig. 12 The "Bloom" Project.

Source: (Sung, 2016)

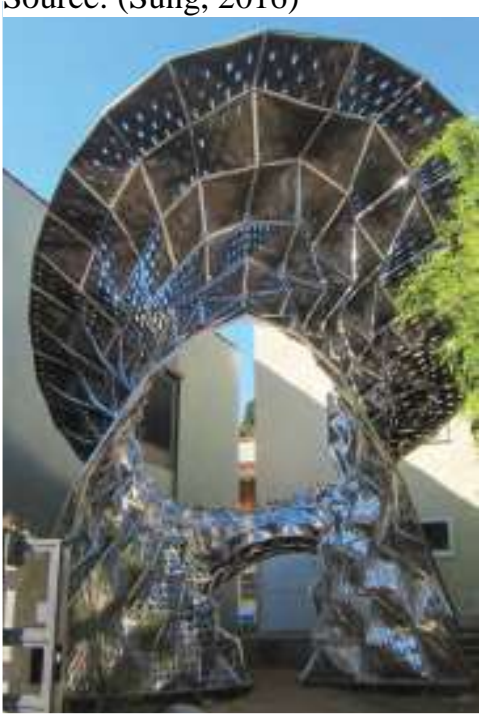

(“HexSphere," Ongoing research, 2014)

The bimetal flexivity is considered Fig. 13 "HexSphere" project. Source: (Sung, 2016) as useful ability in uses in which the potential energy is transformed to kinetic energy. As the temperature increases, the necessity of the material to twist levies stress on the all geometry and this is could be shown in 'HexSphere project' Fig 13.

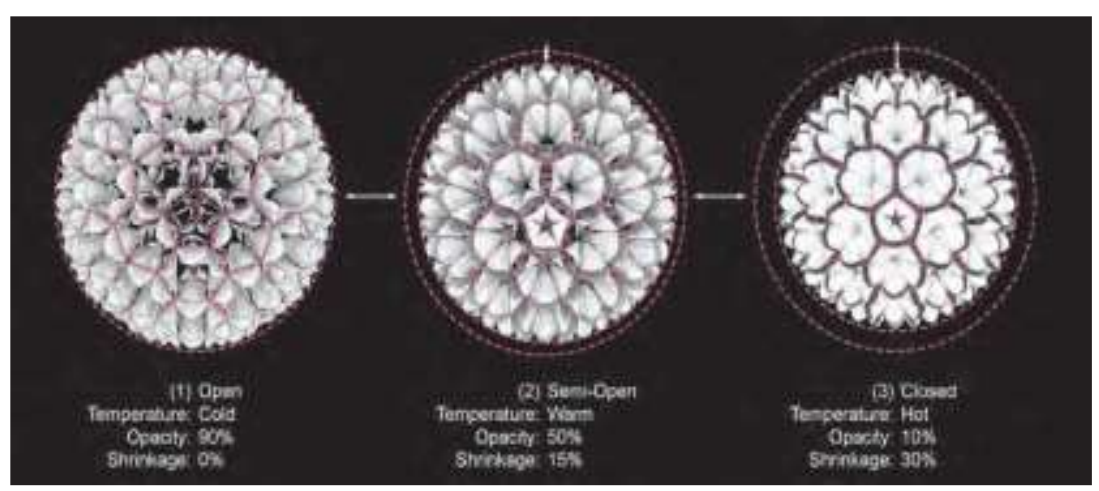

Fig. 14 transformation phases "HexSphere".

This "Hex-Sphere" framework has an individual Source: (Sung, 2016) piece and a whole composite feature of changing shape. Its visual transmitting varieties from highly translucent to mostly opaque. Each piece is consisting of 6 portions of about 0.0025 -inch thick thermobimetal. When it is exposed to heat the already twisted parts will be twisted more, as it exerts more stress to the system, in order to release the stress, the whole composite revolves to

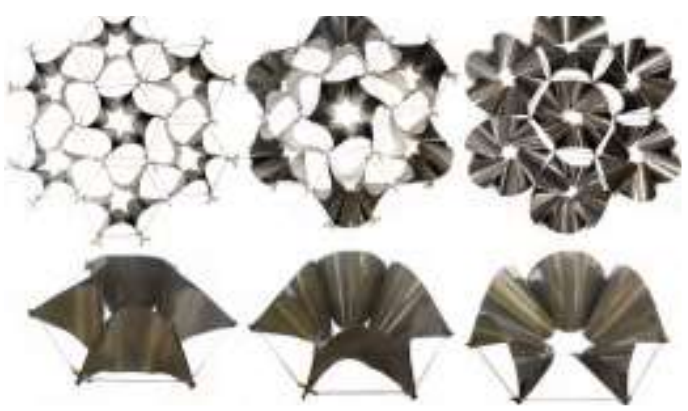
a lower level of energy as it shown in Fig 14.Obviously, the 6 parts unit needs to follow the 
minimum resistance line and will curl from to its ordinary shape into a new shape with new orientation. In that case, the planned outcome is the surface rotate that perpendicular to the base situation. ${ }^{\text {viii }}$

\subsection{Homeostatic Façade Project}

\section{-Self-shading system using Electroactive Polymers (EAPs)}

A Daylight and differences in temperature Fig. 15 Homeostatic Façade. Source:

are considered to be the parameter of a self-regulating façade technique that mechanically regulates to adapt with varying external environments. Decker Yeadon created The Homeostatic Façade technique by controlling the parameters of natural values to save inner envelope in check Fig. 15. Homeostasis is considered to be a natural occurrence in which various organisms control the interior circumstances over various activities. Human sweat is considered as a reaction to heat. The homeostasis facade is depending materia.nl/article/homeostatic-facade-system/ [Date Accessed: 4/12/2017]

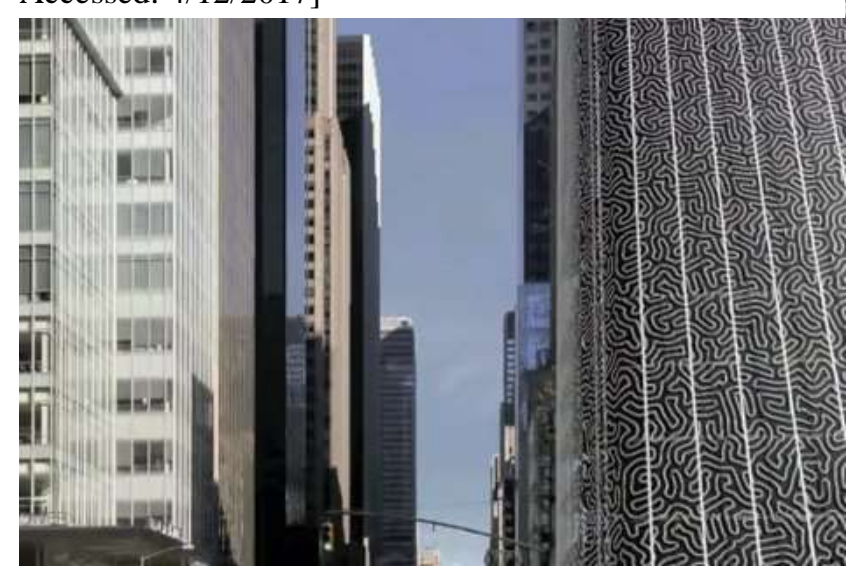
on the standard of dielectric elastomers that permits the building façade technique to regulate the heat gain resulted from the sun. This method is enhanced by the study made by Architectural practice firm, Decker Yeadon based in New York. The façade controls interior circumstances by replying to exterior environmental circumstances. The silver coated elastomer louvers are directly proportional to the presence of the sun, as it opens when brightened by the sun and shut when the sun goes down. The elastomer is activated due the proportional relation between the incident light and the electric charge on the top of the silver coating. By doing so, this technique is in control with the thermal flow which in terms regulates the building internal temperature. Thus, in the presence of low temperature, more light is allowed due to the release of the polymer and vice-versa if there is a high temperature, lesser light is allowed as shown in Fig16. ${ }^{\text {ix }}$

Fig. 16 Visual simulation of Homeostatic Façade System between fully opened and partially opened. Source: materia.nl/article/homeostatic-facade-system/ [Date Accessed: 4/12/2017]

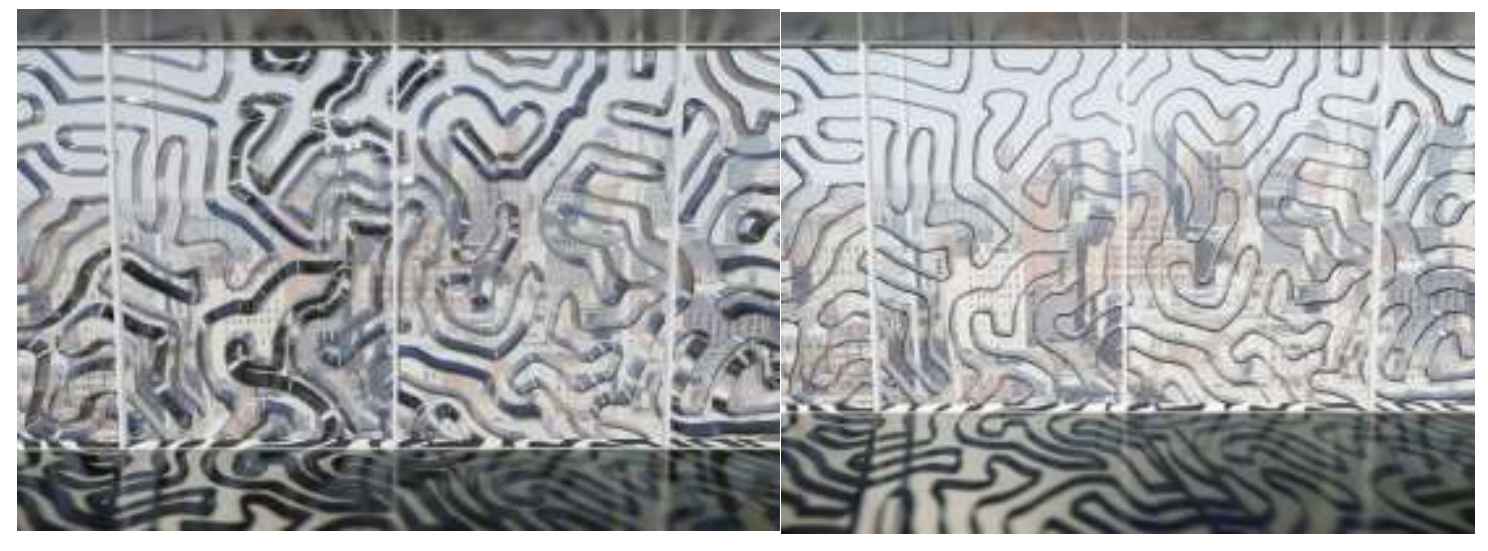




\section{- Biomimicry Inspiration}

The main inspiration for Yeadon's façade technique is muscles, and homeostasis in biological system. The similarity is between the actuator that operates to activate the system in similar with how muscles act Fig. 17. Temperature is an example for the internal conditions regulated by homeostasis organisms. Yeadon's façade controls the building temperature by responding to external environmental changes and conditions. By doing so, they are aware of the local environmental conditions resulting in the usage of locally material and available power.

\subsection{Shape-Shift Project}

\section{- EAP with carbon-based electrodes for façade applications}

Shape shift is considered to be a trial in the materialization of architecture. This research discovers the possible uses of electro-active polymer (EAP) at a scale of architecture and

Fig. 18 Shape-Shift as exhibited at Gallery StarkArt, Zürich.

Source: caad-eap.blogspot.com.eg/p/exhibition_15.html

[Date Accessed: 10/12/2017]
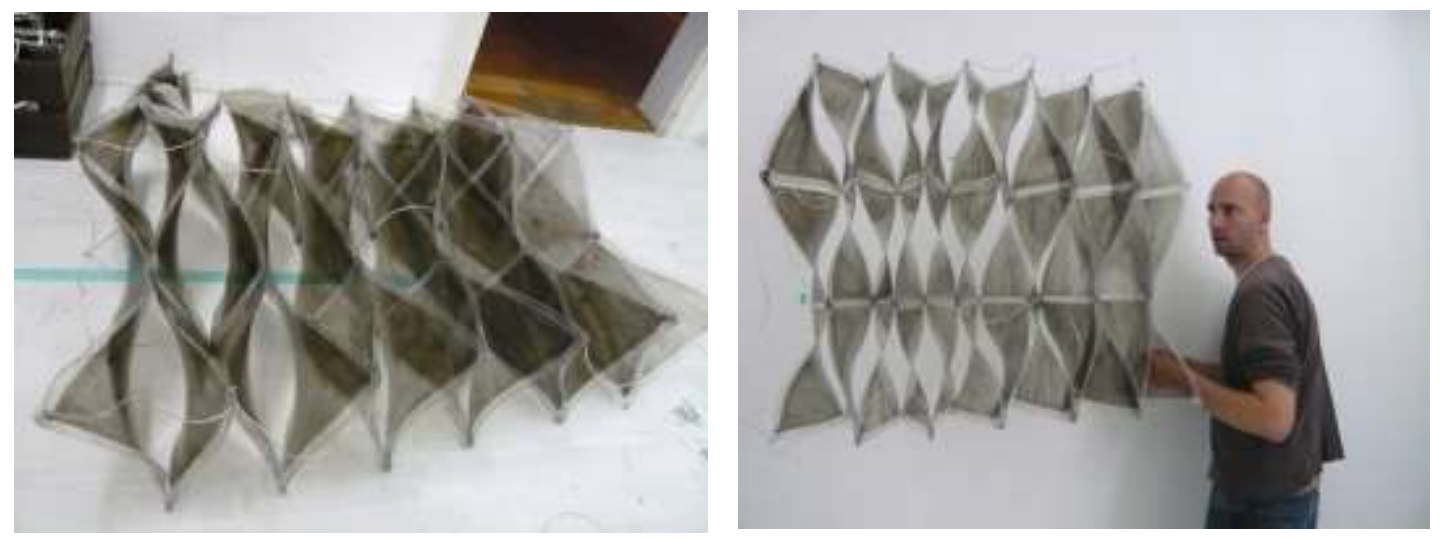

how to maximize the benefit from the EAP. EAP provides a novel interconnection to space built throughout its distinctive potentials properties. It is characterized by an ultra- light weight, elastic material with the capability of changing form deprived of the necessity of motorized actuators. As partnership among the chairperson for ETHZ and EMPA, shape-shift links advanced, unconventional design methods with fabrication and material science while pushing academic experimentation to real worldwide implementation as shown in Fig. 18.

Dielectric elastomers which are special electroactive polymers are used in this project to test the creation of dynamic spatial applications. Dielectric elastomers are considered to be polymer-based actuators that varies in their dimensions in term of shapes, size and volumes directly when exposed to a massive electrical field. These elastomers have a high level of deformation which in terms make them fine, translucent, lightweight and come out from the active materials filed. 
- Electroactive Polymer details EAP is considered to be like a polymer actuator which

- transform electrical force to mechanical power. It is made by inserting an ultrathin layer of elastic acrylic tape across two electrodes. The polymer rubber form is transformed when applying a voltage across the two electrodes with various kilovolts into the following ways:
Fig. 19 Shape-Shift side view.

Source: materiability.com/portfolio/shapeshift/ [Date Accessed: 10/12/2017]

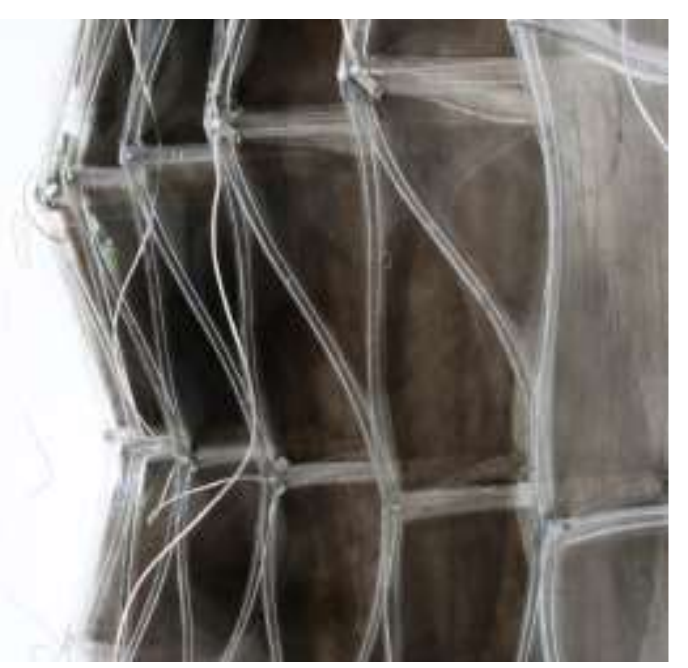

Firstly, the thin film is crushed in its thickness orientation increased to $380 \%$ as a result of the force of attraction between the opposite charges.

Secondly, the thin film is affected by a linear enlargement due to the resisting forces The outcome after activation is that the film turns more thinner and the surface area expands. Also, the supportive frame is bended in case of the acrylic film pre-stretching process due to its flexibility. After applying the voltage, there in an expansion in the material and all the elements level up as shown in fig. 20.across the equal charges.

Fig. 20 elastic acrylic tape sandwiched between two electrodes.

Source: caad-eap.blogspot.com.eg/p/electro-active-polymer.html [Date Accessed: 10/12/2017]
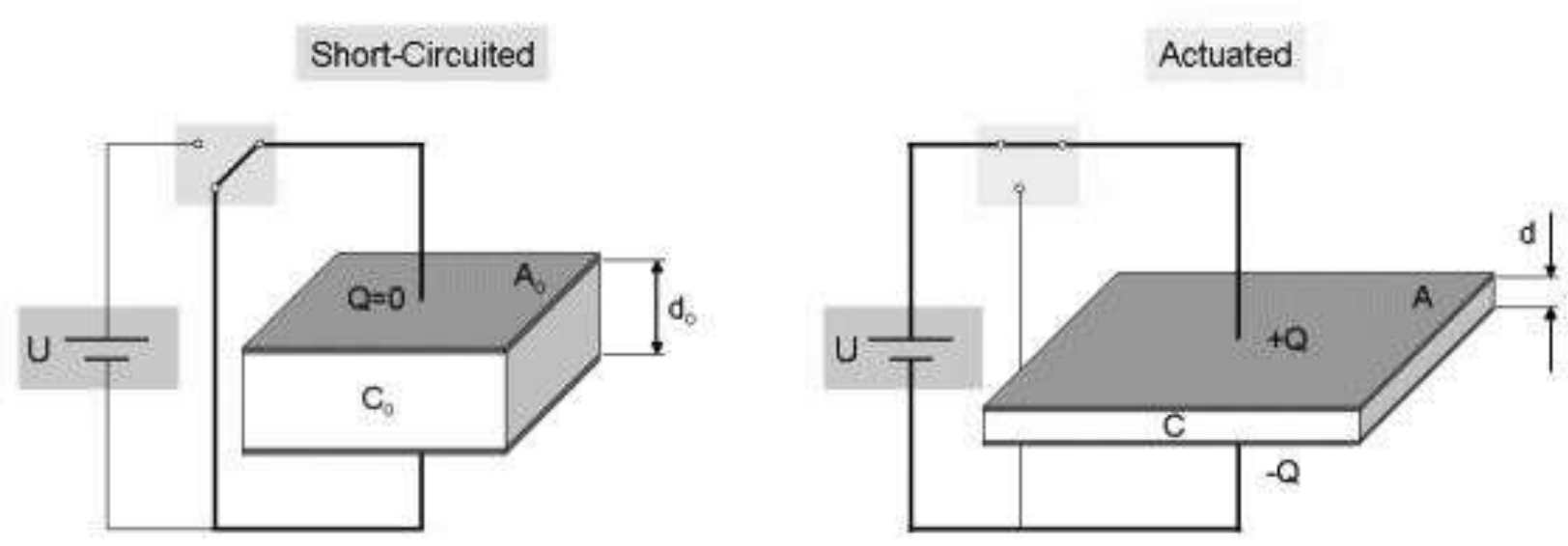

$$
C_{0}=\varepsilon_{0}, \varepsilon_{r} \frac{A_{0}}{d_{0}}<C=\varepsilon_{0} \varepsilon_{r} \frac{A}{d}
$$




\section{GENERATING A PROPOSAL OF A SMART SKIN}

Illustrating a new proposal of smart skin that could be used as a great alternative for any new or existing buildings' facades by applying some features and techniques of merging smart materials with advanced parametric geometries. The approach of reaching the skin will be based on creating a pattern inspired from surrounding nature which consists of smart geometry objects that has the feature to act consistently and Instantaneous without human interference.

\subsection{Application Target}

- Using of variable levels of Smart Materials imbedded in an advanced parametrized shape to create an inspirational pattern that could be used as a new proposal of façade design and screening to create new method of reaching a sustainable stunning environment inside and surround architectural buildings within the city.

- Mimicking local and natural organisms in the surrounding environment as a main inspiration for generating the Pattern and the major techniques that will be used to reform the shape of it.

For that; The main aim in this section is to merge some layers of closure with each other to create a responsive adaptable openness system inspired from local nature by respecting the following:

- Applying an adaptive kinetic pattern on façade openings and windows to create a responsive skin that has a main role in adjusting temperature, lighting and atmosphere inside the building, for reaching a comfort zone in most of the interior envelope with minimum usage of energy decreasing the bad impact on the surrounding environment.

- Reaching that by Inspiring unique pattern units from the local surrounding nature, to create an interactive smart panel which has the ability of control most of façade openings by itself.

- Using of different kind of available smart materials such as electroactive panels imbedded with frames coated with another kind of smart materials for manufacturing and assembling the pattern's units.

\subsection{Smart Skin Form Generation}

\section{Form generation of basic unit and final parametrized Smart system:}

\section{○ Basic unit generation:}

- Shape deformation from straight line polygons with a central state radial core that has a role for connecting between units.

Fig. 21 Abstracting unit from nature. Source: researcher

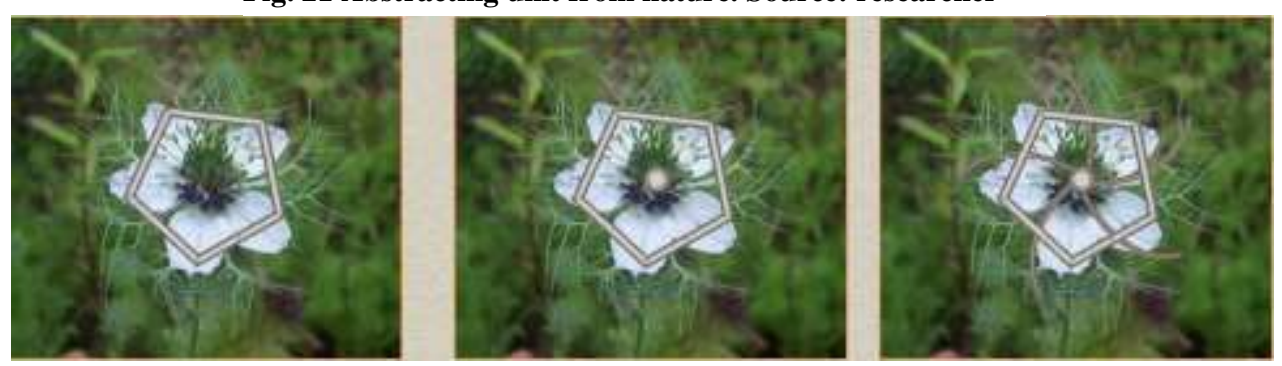


- Inspiring the structural connection between units and the structural mechanism from the abstraction of the outer layer.

Fig. 22 Repetition and rotating around centre. Source: researcher
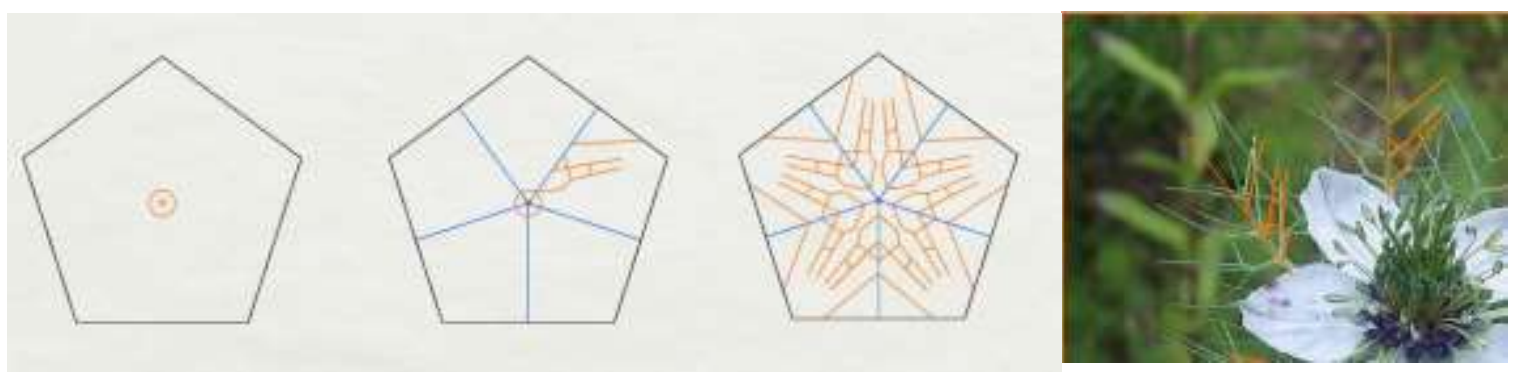

Converting the polygon to the honey-comb hexagonal unit for using the pattern in the most effective way.

Fig. 23 Hexagonal unit. Source: researcher

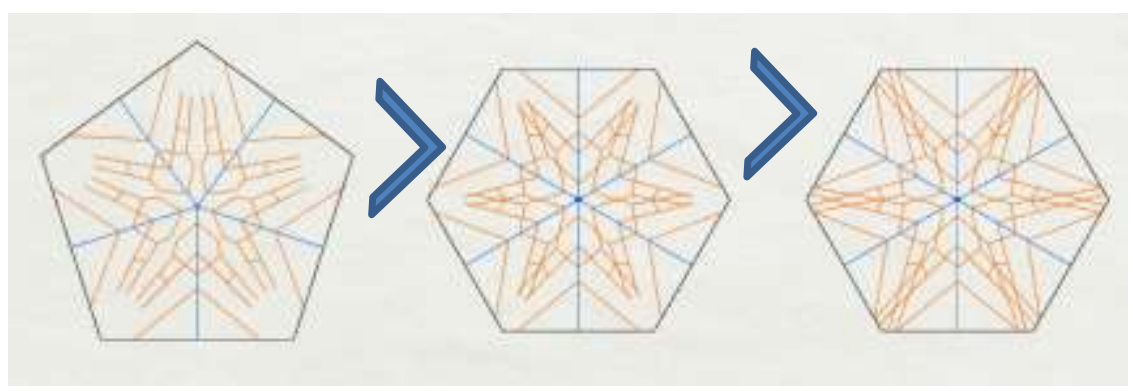

\section{Adaptation Phases:}

The pattern consists of two layers, the internal layer which is used as responsive kinetic shelves where its units revolve to be opened or closed according to different aspects. The external layer acts according to the function of the space, where some functions seeking privacy and other seeking exposure. Testing the connection between units to ensure a stable structure and functions

Fig. 24 Unit adaptation. Source: researcher
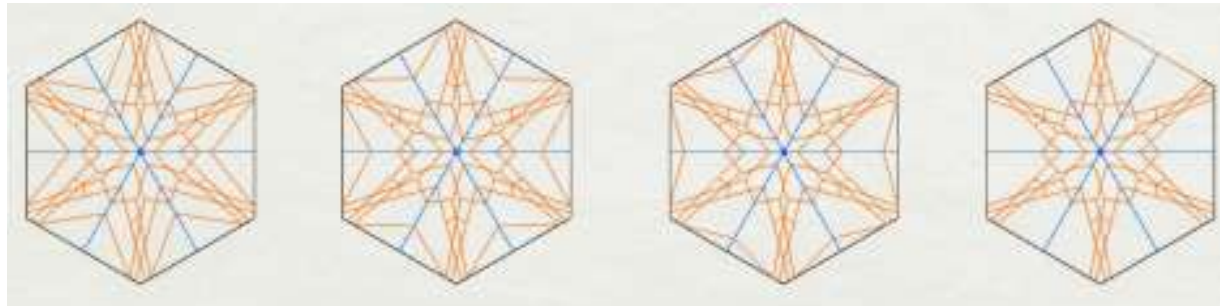
Fig. 25 2D grid testing of the connection between transferred. Source: researcher

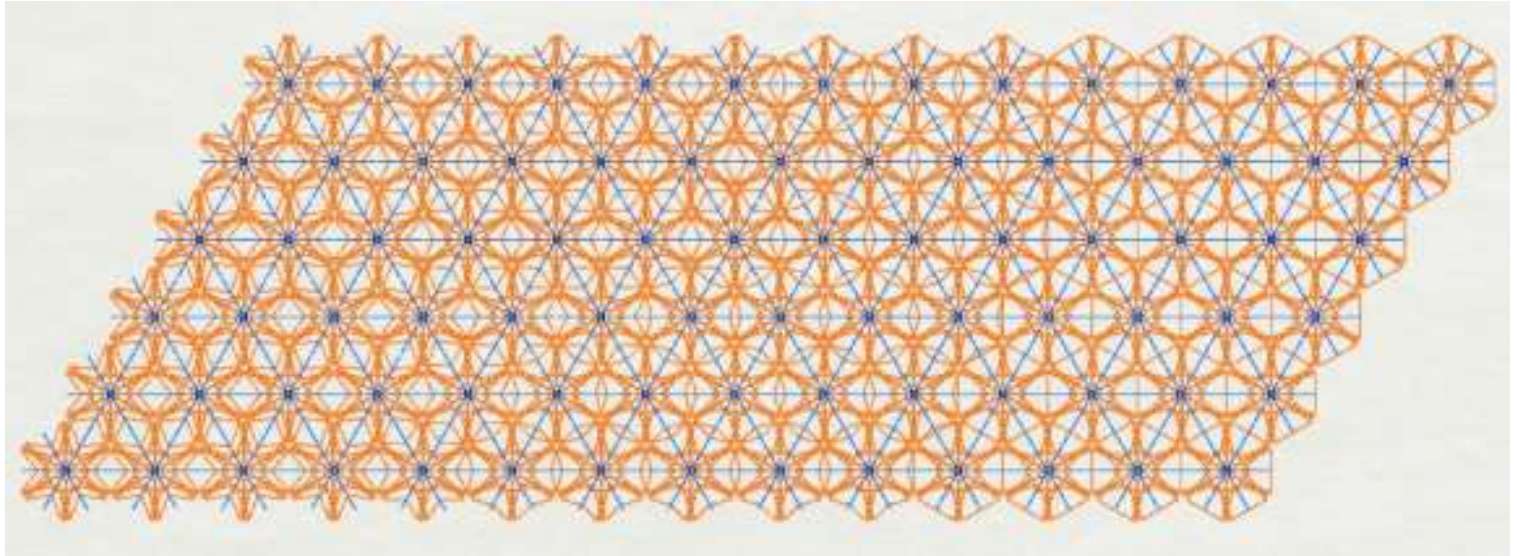

Applying on windows (screen) and openings:

Fig. 26 Final unit. Source: researcher

- Converting the drawing units into 3D interactive and responsive units to create a multi-functional unit that consists of variable features and materials:

- Shading device for preventing the unwanted sun rays

- Small PV cells units - for generating energy that helps in operating the responsive unit sensors and different elements for the building.

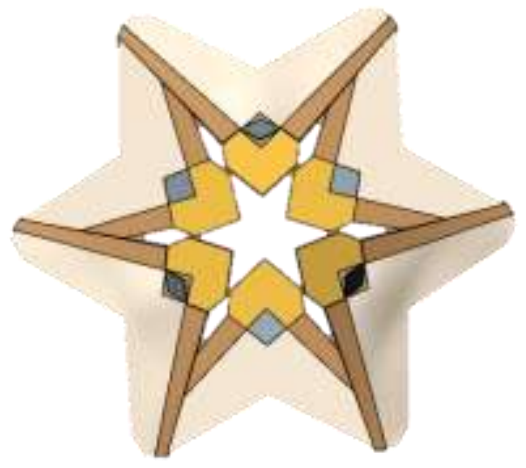

- Phase changing material for helping in adapting the temperature of inner spaces.

- Lighting shelves for increasing the lighting in the interior spaces

- Photo catalyst material (ZO4) which generate oxygen for clarifying the surrounding environment

- The unit's Smart material and geometry mechanism of working:

Fig. 27 3D unit transformation. Source: researcher
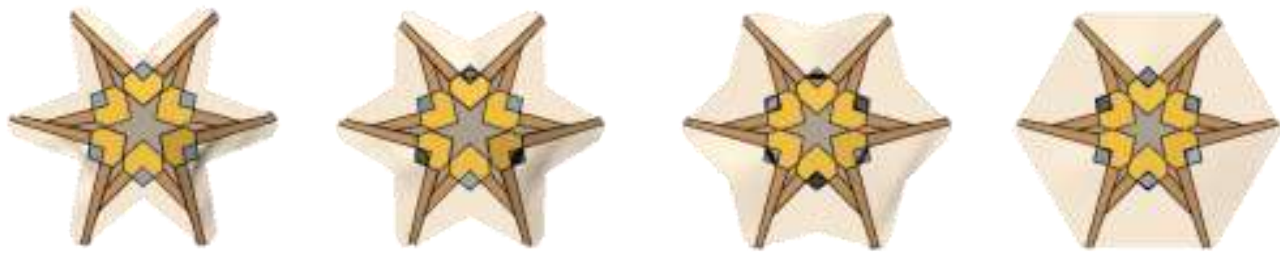

- Shading device: EAP Polymers: the system mainly consists of thin silver coated EAP (electroactive polymer) layers that has the ability to modify its form and return to its original state based on the difference in temperature. The EAP layers are connected and fixed by outer-frames, the main function of this frames generates a 
specific amount of electrical current for custom adjusting of the EAP layers stretching if needed. Also, helping them to bend and modify their shapes more quick than usual. The main role of the composition is to control the amount of penetrated lights into the building.

- PV cells: Each unit has six responsive PV cells which could rotate on an axial axis to collect the sun rays efficiently to be an additional energy source for the building also for operating and processing all kinetics, sensors and electrical current source which embedded in the unit.

- Phase changing material: Each unit has six PCM units which have the ability to store energy and heat to release them inside the space when the degrees of the temperature drops down and vise verse. The PCM materials turns opaque in case of high intensity of lighting and tends to be more transparent in lower intensity.

- Photo catalyst effect: The main function of the frames is to fix the polymers and connect the units with each other. All frames coated with self-cleaning material merged Photo catalyst effect (ZO4) which generates oxygen for clarifying the surrounding environment and make an effect of a planted garden of trees. And the self-cleaning coat is to ensure that the system will work clearly without any dust that could increase the heat gain and decrease the efficiency of the whole skin.

Fig. 28 Final Unit. Source: researcher

structural frames

(Self-cleaning material

merged with Photo

Phase changing

catalyst material (ZO4) material

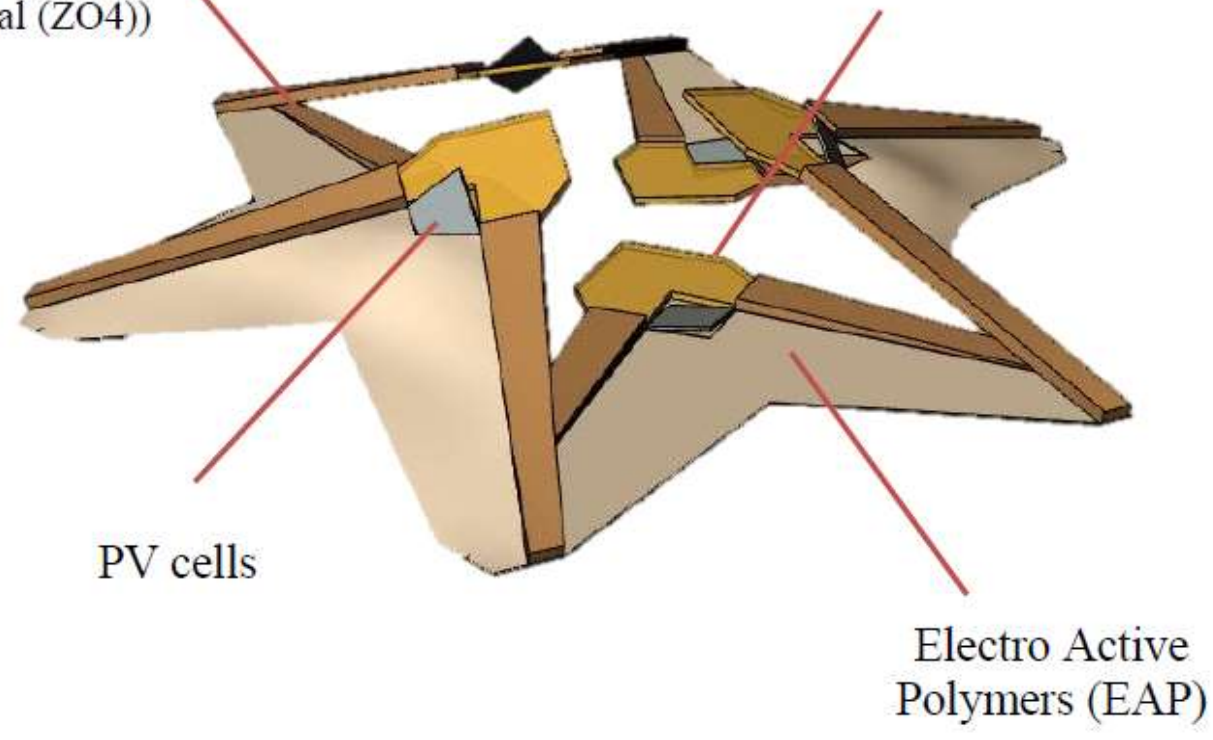

Final output: Environmental and aesthetics aspects.

- This is a sample of connected units with each other presenting different phases and forms that could be gained from variable responsiveness according to: 
- Space lighting requirements

- Sun ray angles

- Space Temperature requirements

- Shading requirements

To reach a comfort zone inside all interior spaces within the building.

Fig. 29 Sample of final pattern according to central focal point. Source: researcher

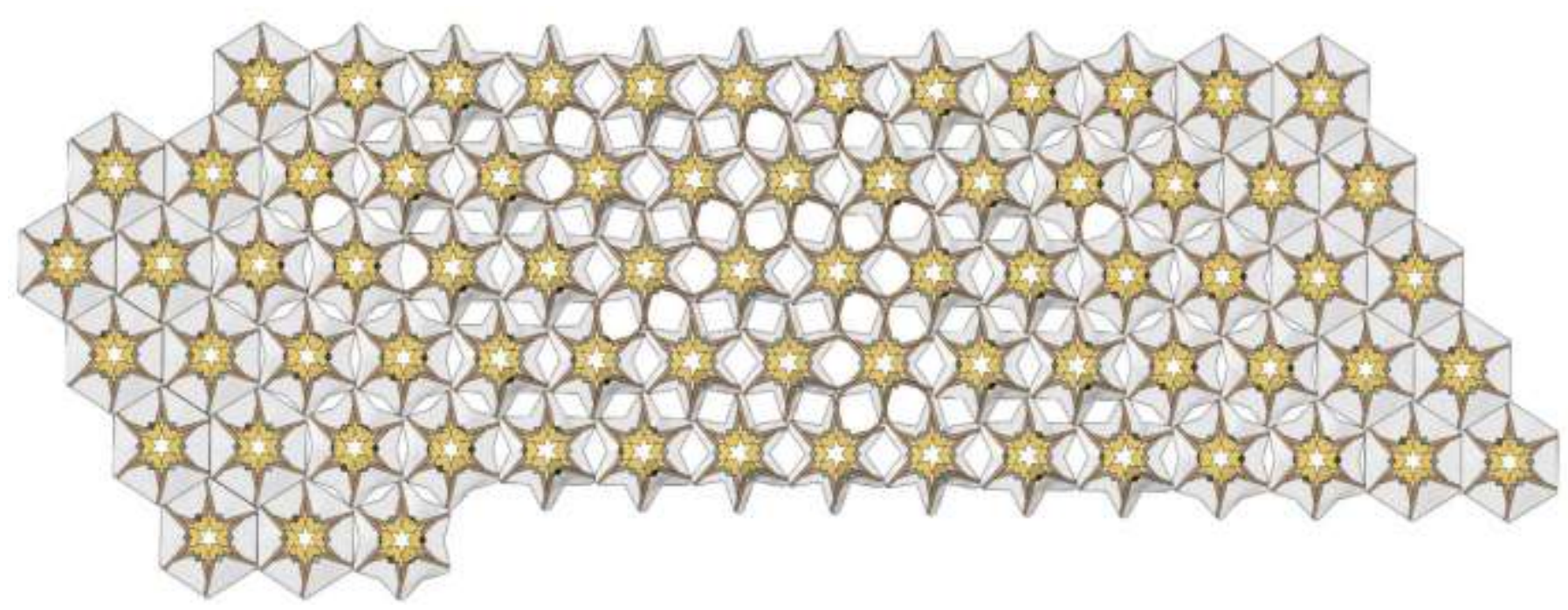

\section{CONCLUSION}

The application of advanced geometries, based on smart materials, has the ability to expressively develop the sustainability of buildings, by focusing on phenomena and not on the material artifact. Energy can be reduced by using individually acting only where necessary and operate separately and locally. Then many of the advantages offered by these technologies can be appropriated by a greater diversity of designs for new structures and retrofitting standing buildings. Material properties are determined by the class of its changing behavior, also by the geometrical form that will add great value to the final composition of material and form integration. So, architects have to understand all material behavior with various fixation and assembling technique in relation to the phenomena and environments they create, Fig. 30 presents a matrix of the application of smart geometries 
Fig. 30 Application of Smart Geometries. Source: researcher based on (Ritter, 2007).

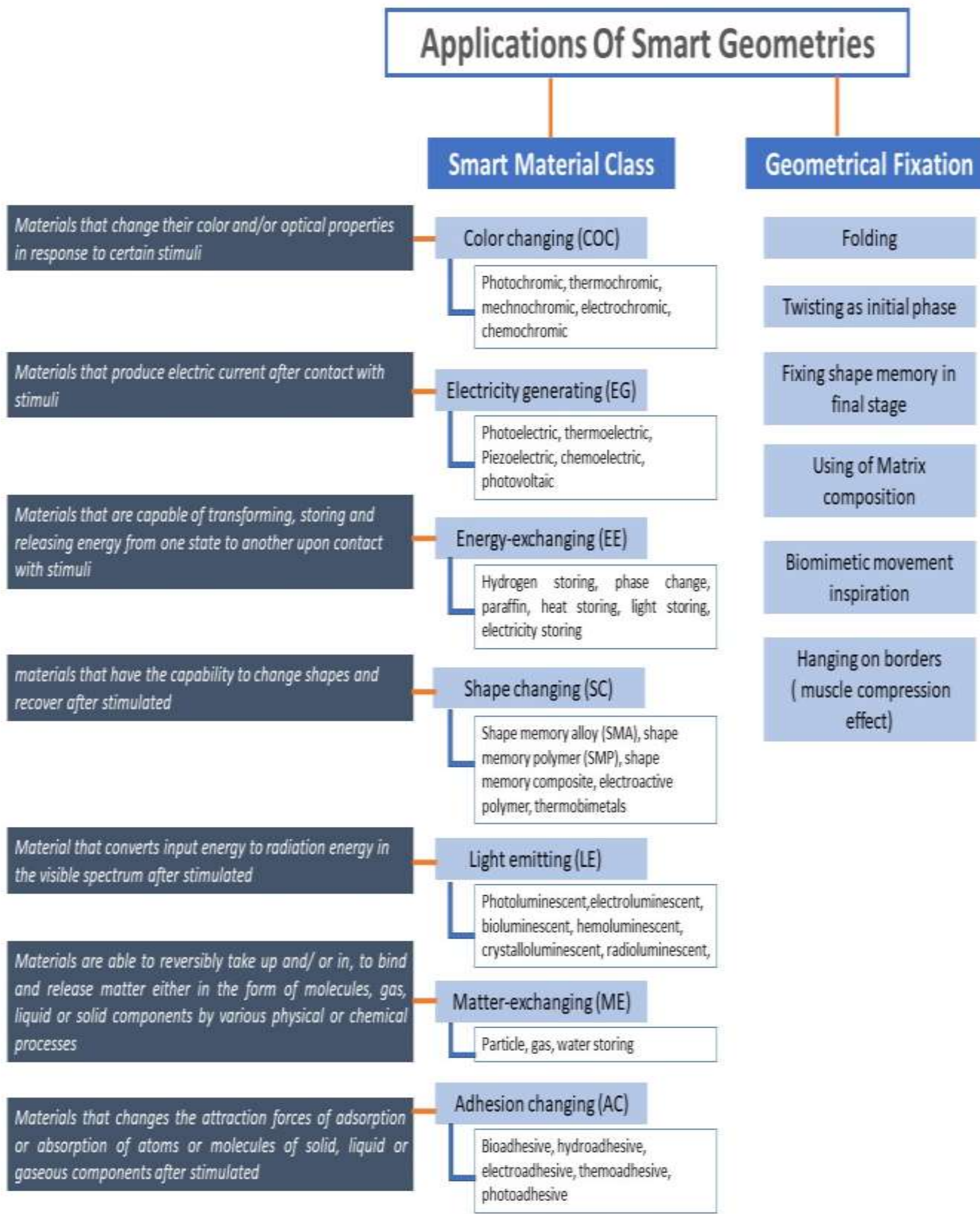




\section{REFERENCES}

${ }^{i}$ Lelieveld, Charlotte, and Liek Voorbij. 'Dynamic Material Application for Architectural Purposes'. Advances in Science and Technology 56 (2008): 595-600.

ii Oosterhuis, K. (2002). Architecture goes wild. Rotterdam, 010 Publishers.

iii Collier, R. and Thelen, E. (2003). User-System Interaction Based on Spoken Dialogue. The New Everyday. E. Aarts and S. Marzano. Rotterdam

iv Lelieveld C. (2013) - Smart Materials For The Realization Of An Adaptive Building Component, TU Delft, Faculty of Architecture, Architectural Engineering + Technology department.

v Lelieveld C. (2013) - Smart Materials For The Realization Of An Adaptive Building Component, TU Delft, Faculty of Architecture, Architectural Engineering + Technology department.

${ }^{v i}$ Johansen, J. M. (2002). Nanoarchitecture a new species of architecture. New York, Princeton Architectural Press.

viiKutz, (2002), Handbook of Material Selection, John Wiley \& Sons Inc, New York.

viiiHarvey, (1998), Kirk-OthmerEncyclopedia of chemical technology, John Wiley \& Sons Inc, New York.

${ }^{\mathrm{ix}}$ NASA ,2012, Retrieved Sep. 21, 2015: http://www.virtualskies.arc.nasa.

${ }^{\mathrm{x} E n c y c l o p e d i a}$ of chemical technology, Retrieved Sep. 21, 2015.

xi Addington, M., Shodek, D. ( 2005 ), Smart materials and new technologies (for architecture and design professions), Harvard University, U.S.A.

xii Turrin, M., Tenpierik, M., de Ruiter, P., van der Spoel, W., Chang Lara, C., Heinzelmann, F.,Teuffel, P., \& van Bommel, W. (2014). DoubleFace: Adjustable translucent system to improve thermal comfort. SPOOL, 1(2), 5-9.

xiii Turrin, M., Tenpierik, M., de Ruiter, P., van der Spoel, W., Chang Lara, C., Heinzelmann, F.,Teuffel, P., \& van Bommel, W. (2014). DoubleFace: Adjustable translucent system to improve thermal comfort. SPOOL, 1(2), 5-9.

xiv Albert G. Dietz, ed., (1999) Composite Engineering Laminates (Cambridge, MA: MIT Press, 1969), chap. 10; and Carpenter Controlled Expansion Alloys ,CRS Holdings.

${ }^{x v}$ Farshid M. (2009), Function of Form , Cambridge,MA: Actar/Harvard GSD.

xvi Jules M., ( 2011) Designing Kinetics for the Architectural Facades: State Change, New York: Routledge.

xvii Doris Sung (2016) Smart Geometries for Smart Materials: Taming Thermobimetals to Behave, Journal of Architectural Education, 70:1, 96-106

xviii Doris Sung (2016) Smart Geometries for Smart Materials: Taming Thermobimetals to Behave, Journal of Architectural Education, 70:1, 96-106

xix Minner , K.( 2011) "Moving Homeostatic Facade Preventing Solar Heat Gain". ArchDaily. Accessed January 18, 2017. http://www.archdaily.com/101578 